\title{
Diálogos sobre a descentralização do programa de controle da hanseníase em município endêmico: uma avaliação participativa ${ }^{a}$
}

\author{
Dialogues on the decentralization of the leprosy control program in an endemic municipality: a
} participatory evaluation

\section{Diálogos sobre la descentralización del programa de control de la lepra en un municipio endémico: una evaluación participativa}

\author{
Cristal Marinho Corrêa ${ }^{1}$ (1) \\ Fernanda Moura Lanza² (1) \\ Ana Paula Mendes Carvalho ${ }^{3}$ (I) \\ Francisco Carlos Félix Lana ${ }^{1}$ (B)
}

1. Universidade Federal de Minas Gerais,

Programa de Pós-Graduação em Enfermagem.

Belo Horizonte, MG, Brasil.

2. Universidade Federal de São João del-Rei, Programa de Pós-Graduação em Enfermagem. Divinópolis, MG, Brasil.

3. Secretaria de Estado de Saúde de Minas Gerais. Belo Horizonte, MG, Brasil.
Autor correspondente:

Ana Paula Mendes Carvalho.

E-mail: carvalho.anapaulam@gmail.com

Recebido em 23/04/2021.

Aprovado em 04/10/2021.

DOI:https://doi.org/10.1590/2177-9465-EAN-2021-0114

\section{Resumo}

Objetivo: avaliar a descentralização do Programa de Controle da Hanseníase (PCH) em Governador Valadares. Método: o referencia teórico-metodológico foi a Avaliação de Quarta Geração, de abordagem qualitativo-participativa. O estudo envolveu 30 sujeitos divididos em quatro grupos: gestores do $\mathrm{PCH}$; profissionais do Centro de Referência (CR); profissionais da atenção básica e usuários. Os dados foram coletados por entrevistas, utilizando-se a técnica do Círculo Hermenêutico-Dialético. Posteriormente, realizaram-se três oficinas de validação e negociação dos dados. Utilizou-se o Método Comparativo Constante para a análise. Resultados: evidenciou-se a manutenção do modelo vertical de atenção à hanseníase, sustentado por determinantes sócio-histórico-culturais que se expressam: na permanência da porta de entrada à demanda espontânea no CR; no encaminhamento rotineiro do usuário para a atenção secundária; na ineficiência da contrarreferência; na centralização da poliquimioterapia; na crença na necessidade do atendimento especializado e no estigma. Evidenciaram-se fragilidades no vínculo com a atenção primária. Conclusão: a descentralização do PCH envolve a tensão entre os atores de cada ponto de atenção à saúde, gerando disputas de saberes e práticas de saúde. Implicações para a prática: a sustentabilidade da descentralização requer envolvimento político e institucional focado no fortalecimento da atenção primária, na reorientação do papel dos serviços na rede de atenção à hanseníase e na educação em saúde.

Palavras-chave: Atenção Primária à Saúde; Avaliação em Saúde; Descentralização; Hanseníase; Pesquisa Qualitativa.

\begin{abstract}
Objective: to evaluate the decentralization of the Leprosy Control Program (LCP) in Governador Valadares. Method: the theoretical and methodological framework was the Fourth Generation Evaluation, with a qualitative-participatory approach. The study involved 30 subjects divided into four groups: managers of the LCP; professionals of the Reference Center (RC); primary care professionals and users. Data were collected through interviews, using the Hermeneutic-Dialectic Circle technique. Subsequently, three workshops were held for data validation and negotiation. The Constant Comparative Method was used for the analysis. Results: the maintenance of the vertical model of leprosy care was evidenced, sustained by social-historical-cultural determinants that are expressed in: the permanence of the gateway to spontaneous demand in the RC; the routine referral of the user to secondary care; the inefficiency of counter-reference; the centralization of multidrug therapy; the belief in the need for specialized care, and stigma. Weaknesses in the link with primary care were evidenced. Conclusion: the decentralization of the LCP involves tension between the actors of each health care point, generating disputes of knowledge and health practices. Implications for practice: the sustainability of decentralization requires political and institutional involvement focused on strengthening primary care, reorienting the role of the services in the leprosy care network, and health education.
\end{abstract} Keywords: Decentralization; Health Evaluation; Leprosy; Primary Health Care; Qualitative Research.

\section{Resumen}

Objetivo: evaluar la descentralización del Programa de Control de la Lepra (PCL) en Governador Valadares. Método: el marco teórico-metodológico fue la Evaluación de Cuarta Generación, con un enfoque cualitativo-participativo. El estudio involucró a 30 sujetos, divididos en cuatro grupos: gerentes del PCL; profesionales del Centro de Referencia (CR); profesionales de atención primaria y usuarios. Los datos fueron recolectados a través de entrevistas, utilizando la técnica del Círculo HermenéuticoDialéctico. Posteriormente se realizaron tres talleres de validación y negociación de los datos. Para el análisis se utilizó el Método Comparativo Constante. Resultados: se evidenció el mantenimiento del modelo vertical de atención a la lepra, sustentado en determinantes socio-histórico-culturales que se expresan en la permanencia del ingreso a la demanda espontánea en el CR en la derivación rutinaria del usuario a atención secundaria; en la ineficiencia de la contrarreferencia; en la centralización de la poliquimioterapia; en la creencia en la necesidad de atención especializada y en el estigma. Se evidenciaron debilidades en el vínculo con la atención primaria. Conclusión: la descentralización del PCH involucra la tensión entre los actores en cada punto de la atención en salud, generando disputas sobre conocimientos y prácticas de salud. Implicaciones para la práctica: la sostenibilidad de la descentralización requiere de una participación política e institucional, enfocada en el fortalecimiento de la atención primaria, reorientando el rol de los servicios en la red de atención a la lepra y en la educación para la salud.

Palabras clave: Atención primaria de salud; Evaluación en salud; Descentralización; Lepra Investigación cualitativa. 


\section{INTRODUÇÃO}

A hanseníase é uma doença endêmica no Brasil que afeta, desigualmente, pessoas de diferentes etnias que vivem em situações precárias de vida, principalmente as de baixa renda e escolaridade ${ }^{1}$. A redução da carga global da hanseníase depende do grau de organização dos serviços de saúde para a ampliação da oferta de ações como: investigação epidemiológica para o diagnóstico oportuno dos casos; tratamento com a poliquimioterapia (PQT) até a cura; prevenção e tratamento das incapacidades físicas; educação em saúde com foco no combate ao estigma e na educação permanente dos profissionais de saúde e exame dos contatos domiciliares e sociais ${ }^{2}$.

$\mathrm{Na}$ rede de atenção à hanseníase, têm-se os serviços de Atenção Primária à Saúde (APS) como principal porta de entrada e ordenadora do cuidado a fim de detectar, precocemente, a doença, favorecer o acesso do usuário, reduzir o estigma e garantir a integralidade da assistência ${ }^{3-4}$.

O desafio da descentralização (ou integração) das ações de controle da hanseníase $(\mathrm{ACH})$ na APS é uma realidade no Brasil $^{5}$ e no mundo ${ }^{6}$ e reflete-se na elevada concentração de diagnósticos e tratamentos em ambulatórios especializados ${ }^{7}$.

Os estudos avaliativos sobre a descentralização das $\mathrm{ACH}$ na APS brasileira versam sobre o monitoramento dos indicadores epidemiológicos e operacionais ${ }^{8}$, as avaliações normativas ${ }^{9-10}$, o grau de implantação do Programa de Controle da Hanseníase $(\mathrm{PCH})^{11-12}$ e a presença e extensão dos atributos da APS na realização das $\mathrm{ACH}^{13-15}$. No diversificado arcabouço teóricometodológico dos estudos avaliativos, os enfoques emergentes têm sido propostos como alternativa para viabilizar os modelos participativos de avaliação que levam em consideração, também, o protagonismo de atores sociais inseridos no contexto sociopolítico e cultural dos programas e políticas de saúde ${ }^{16}$. Acredita-se que essas relações, histórica e socialmente estabelecidas, determinam a construção do modelo de atenção à doença, delimitando o papel dos serviços na rede municipal e as condições de sustentabilidade do processo de descentralização.

A justificativa e a relevância deste estudo dão-se pela necessidade de compreensão dos aspectos que se interpõem à descentralização das ACH em Governador Valadares (Minas Gerais) por tratar-se de um município de elevada endemicidade e um dos pioneiros na implantação do $\mathrm{PCH}$ no Brasil ${ }^{17}$. Nesta perspectiva, o objetivo deste estudo foi avaliar a descentralização do Programa de Controle da Hanseníase em Governador Valadares.

\section{MÉTODOS}

Pesquisa qualitativa, de abordagem participativa, fundamentada no paradigma construtivista responsivo da Avaliação de Quarta Geração $^{18}$.

Trata-se de uma avaliação de saúde, com abordagem avaliativa emergente ${ }^{16}$, na qual os parâmetros e limites da avaliação não são determinados de antemão pelo avaliador e sim estabelecidos por meio de um processo evolutivo, interativo e iterativo, que envolve a negociação com grupos de interesse potencialmente afetados pela avaliação, favorecendo o diálogo, a reflexão crítica e a compreensão mútua dos diferentes atores sociais envolvidos ${ }^{19}$

O estudo foi desenvolvido em Governador Valadares, um dos municípios de Minas Gerais com elevada concentração de casos, cujo coeficiente de detecção de casos novos de hanseníase, em 2019, foi de 32,7 casos/100 mil habitantes, o que classifica o seu grau de endemicidade como muito elevado?

O município de Governador Valadares implantou o PCH ainda no ano de 1943 mediante as ações do Serviço Especial de Saúde Pública $(\mathrm{SESP})^{20}$. A rede municipal de atenção à hanseníase é composta, principalmente, pelo Hospital Municipal de Governador Valadares, pelo Centro de Referência para Programas e Doenças Especiais (CREDENPES) e pelas unidades básicas de saúde distribuídas entre as regiões sanitárias do município.

A pesquisa foi conduzida em sete etapas: apresentação da proposta de pesquisa à Secretaria Municipal de Saúde de Governador Valadares; organização e planejamento do trabalho de campo; entrada do pesquisador em campo e identificação dos grupos de interesse (stakeholders); aplicação do Círculo Hermenêutico-Dialético e análise simultânea dos dados; reanálise dos dados; Oficinas de Negociação e Validação ${ }^{18}$.

Foram elaborados roteiros semiestruturados contendo perguntas disparadoras a respeito da atuação dos serviços de atenção primária, secundária e terciária nas $\mathrm{ACH}$ e sobre o processo de descentralização das $\mathrm{ACH}$ no município. Realizaramse quatro testes pilotos com enfermeiros e Agentes Comunitários de Saúde (ACS), em um Centro de Saúde de Belo Horizonte, que permitiram identificar a necessidade de adaptações de linguagem no instrumento para favorecer a reflexão crítica dos atores.

A inclusão de participantes no estudo deu-se, a posteriori, após a entrada do pesquisador em campo, entre 14 e 17 de junho de 2015, por meio de um processo de negociação que envolveu gestores e profissionais de saúde de diversas categorias e cargos municipais mediante três reuniões com o pesquisador em diferentes serviços.

Levaram-se em consideração os seguintes aspectos negociados com os atores: o interesse espontâneo à participação no estudo, a inclusão de lideranças políticas municipais, personagens envolvidos na militância histórica do $\mathrm{PCH}$ no município, além da importância da variabilidade de categorias profissionais.

Considerou-se relevante a participação de usuários na avaliação, optando-se pela seleção aleatória de sujeitos que concluíram o tratamento há, no máximo, um ano a partir da data da coleta e cuja entrada no $\mathrm{PCH}$ se deu por diferentes modos, dentre eles, demanda espontânea e encaminhamento pela APS. Ressalta-se que, na ocasião da pesquisa e em um período retrospectivo de dois anos, não havia usuários que foram acompanhados pela APS no município. Utilizaram-se, inicialmente, as fichas de acompanhamento do SINAN como fonte de obtenção de informações sobre os usuários e foi solicitado que os profissionais do serviço de referência local CREDENPES - realizassem o primeiro contato para o convite à 
participação no estudo e a autorização de contato posterior do pesquisador responsável para o agendamento e a entrevista.

O processo de negociação dos participantes resultou na seleção prévia de 30 sujeitos (stakeholders) divididos em quatro grupos de interesse: gestores municipais (quatro); profissionais do centro de referência (11); profissionais da APS (nove) e usuários (seis).

A primeira etapa da coleta de dados ocorreu entre $14 \mathrm{e}$ 29 de junho de 2015 após a identificação dos stakeholders e correspondeu à aplicação do Círculo Hermenêutico-Dialético com os quatro grupos de interesse. Esta ferramenta consiste na realização de entrevistas individuais sobrepostas a partir de uma dinâmica de círculo que permite que os sujeitos confrontem suas opiniões e posicionamentos sobre o objeto de investigação ${ }^{18}$.

A Figura 1 representa o diagrama da dinâmica de aplicação do Círculo Hermenêutico-Dialético.

Inicialmente, era realizada uma entrevista com um respondente inicial (R1), disparando-se questões norteadoras do roteiro semiestruturado. Os temas centrais, conceitos, ideias, valores, problemas e questões propostos pelo respondente (R1) eram analisados pelo pesquisador em uma formulação inicial designada (C1). Em seguida, um segundo respondente (R2) do mesmo grupo de interesse era entrevistado. Após a exposição de suas questões iniciais, os temas da análise (de R1) eram introduzidos e o R2, convidado a comentá-los. Como resultado, constatava-se a reelaboração de posicionamentos, relativização e/ou reafirmação de conceitos iniciais por parte de R2, possibilitando uma construção mais rica e sofisticada designada (C2). O processo era repetido por meio da adição de novos informantes até a conclusão das entrevistas de todos os integrantes do mesmo grupo, fechando-se, assim, o círculo ${ }^{18}$.
As entrevistas tiveram duração média de uma hora. A análise deu-se concomitantemente à coleta e foi repetida após o término do Círculo Hermenêutico-Dialético a fim de ampliar a identificação de informações possivelmente despercebidas durante o processo dinâmico de sua aplicação. As entrevistas foram transcritas na íntegra. Foi utilizado, como técnica de análise, o Método Comparativo Constante, inicialmente formulado pela Grounded Theory de Glaser e Strauss ${ }^{21}$, com posteriores reformulações teóricas no sentido de incorporar o princípio da interpretação, marca característica do construtivismo ${ }^{22}$, e adequar o método à Avaliação de Quarta Geração ${ }^{18}$.

A análise deu-se em cinco etapas: transcrição das entrevistas; leitura flutuante do material empírico; codificação dos dados e sua comparação constante com o conteúdo de novas entrevistas agregadas; desenvolvimento de teoria mediante a construção de categorias heurísticas e subcategorias; verificação de saturação dos dados qualitativos para a decisão sobre a continuidade ou interrupção do Círculo Hermenêutico-Dialético ${ }^{18}$.

A manutenção de conflitos de interesse e os pontos críticos de divergência acerca do objeto da avaliação, após a dinâmica do Círculo Hermenêutico-Dialético, foram os critérios que direcionaram a opção do pesquisador pela preparação das agendas de negociação. Desta forma, a segunda etapa da coleta de dados consistiu na realização de três oficinas de negociação e validação dos dados com os participantes, sendo uma com profissionais da APS, uma com profissionais do centro de referência e uma com gestores, ocorridas entre os dias 3 e 4 de dezembro de 2015. O objetivo das oficinas foi discutir as divergências em pauta, ampliar os consensos ou tornar mais claros os pontos em divergência e partilhar, com os atores, a análise feita pelo pesquisador, buscando a validação participativa dos

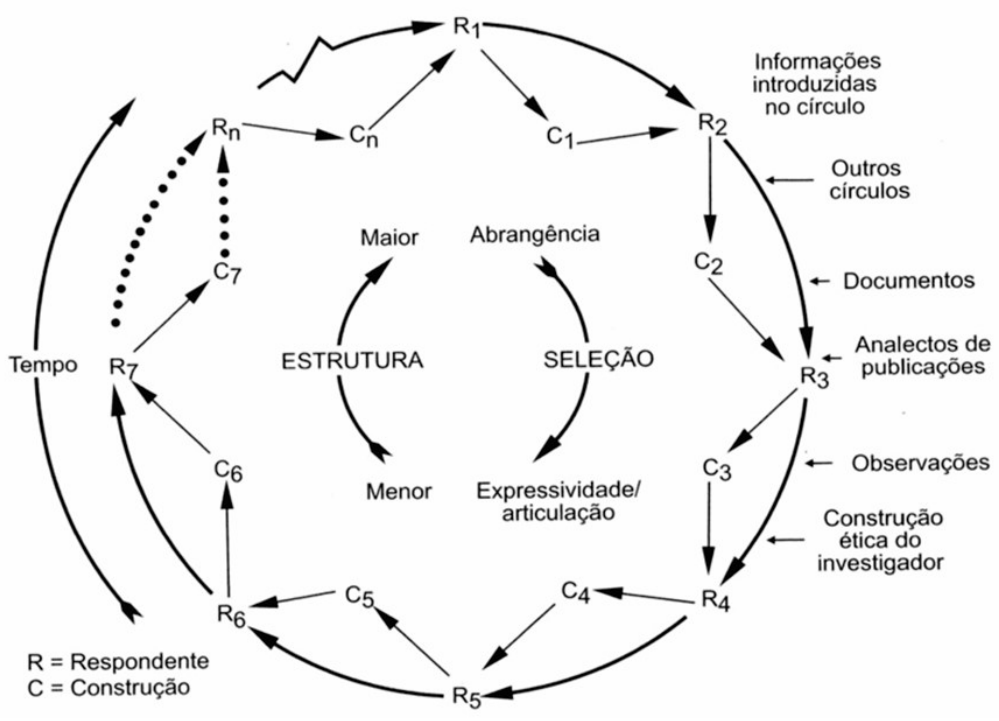

Figura 1. Círculo Hermenêutico-Dialético. Fonte: Guba e Lincoln ${ }^{18: 169}$ 
resultados da avaliação. Foi entregue a cada participante, com antecedência de 48 horas, a cópia da transcrição das entrevistas realizadas no Círculo Hermenêutico-Dialético juntamente com um relatório de pautas contendo as divergências que seriam discutidas. $\mathrm{O}$ objetivo foi viabilizar o material necessário para a reflexão crítica dos atores antes de sua imersão nas oficinas e possibilitá-los, também, a oportunidade de apontar eventuais erros na transcrição de suas entrevistas.

Durante as oficinas, foi apresentado o modelo de construção das categorias por meio de quadros explicativos, contendo núcleos temáticos (categorias), unidades de informação (subcategorias) e exemplos de fragmentos de falas dos entrevistados, partilhando, com os sujeitos, a lógica de categorização utilizada pelo pesquisador. As oficinas tiveram duração média de duas horas, foram gravadas e o conteúdo referente às negociações e pactuações, consolidado em formato de texto em ata. Não houve solicitações de alteração no documento final das oficinas.

Esta pesquisa foi realizada por pesquisadores do Núcleo de Estudos e Pesquisas em Hanseníase (NEPHANS) da Universidade Federal de Minas Gerais (UFMG). Seguiu as normatizações da Resolução no 466/2012 do Conselho Nacional de Saúde e foi aprovada pelo Comitê de Ética em Pesquisa da UFMG com o Parecer consubstanciado ${ }^{\circ} 1.076 .302$. A participação dos sujeitos foi voluntária mediante a assinatura do Termo de Consentimento Livre e Esclarecido após serem informados sobre os objetivos e possíveis riscos do estudo. As falas dos participantes foram codificadas no texto por meio de siglas alfanuméricas com ordem aleatorizada para gestores (GES), Profissionais do Centro de Referência (PCR), Profissionais da APS (PAPS) e Usuários (US) a fim de proteger o anonimato dos participantes.

\section{RESULTADOS}

Serão apresentados os dados das entrevistas individuais realizadas por meio do Círculo Hermenêutico-Dialético, validadas nas oficinas de negociação, que compuseram o núcleo temático "Diálogos sobre o modelo de atenção à hanseníase: a problemática da descentralização na visão dos atores municipais".

Na primeira fase do estudo, participaram das entrevistas do Círculo Hermenêutico-Dialético 30 sujeitos. No grupo de gestores (GES), composto por quatro sujeitos, foram incluídos profissionais que ocupavam cargos diretivos na APS municipal, referências técnicas e profissionais do setor de Vigilância Epidemiológica.

No grupo "Profissionais do Centro de Referência" (PCR), foram incluídos 11 sujeitos, dentre eles, dois médicos, um enfermeiro, um técnico de Enfermagem, um assistente social, um terapeuta ocupacional, um psicólogo, um bioquímico, um visitador sanitário, um gerente administrativo e um ex-funcionário do serviço reivindicado pelos atores devido ao seu histórico de militância pelo $\mathrm{PCH}$ no município.

Os nove sujeitos que compuseram o grupo de interesse "Profissionais da Atenção Primária à Saúde" (PAPS) foram compostos por três médicos, três enfermeiros e três ACS. No grupo de usuários (US), foram inclusos quatro sujeitos.
$\mathrm{Na}$ segunda fase do estudo, participaram das Oficinas de Negociação e Validação nove dos 11 profissionais do CR $(82 \%)$ entrevistados na primeira fase do estudo, sete dos nove profissionais da APS (78\%) e três dos quatro gestores (75\%), além de ouvintes reivindicados pelos atores e acatados pelo pesquisador após negociação.

Um dos pontos mais debatidos como entrave à descentralização foi a manutenção histórica da porta de entrada do CREDENPES - unidade de atenção secundária - à demanda espontânea no município.

[...] a gente escuta o discurso, né [...] - "Ah, não, mas a atenção básica não faz"-, mas não faz por quê? Porque tem quem faz! Por que pré-natal faz? Por que hipertensão e diabetes faz? Já pensou se eu tivesse uma policlínica com endocrinologista porta aberta? la ser a mesma coisa. Já pensou se eu tivesse um CVV (Centro Viva Vida) com porta aberta pra pré-natal? la ser a mesma coisa. [...] GES2

[...] Ele vem direto. Se você quiser controlar uma doença infectocontagiosa, você tem que facilitar ao máximo, se começar a dificultar, né, você perde o doente. [...] você vai mandar ele pra posto, complicar a vida dele? [...] PCR11

[...] Se o CREDENPES for fechado, fechado, que eu digo, a porta, se dificultar o acesso ao CREDENPES aonde você só teria como ir com encaminhamento, $O$ quê que vai acontecer? Esse paciente não vai vir no posto porque: - "eu não quero me expor, a ACS [Agente Comunitário de Saúde] é minha vizinha, fala muito, vai sair falando pra todo mundo que eu tive no posto por causa de uma mancha, então eu não vou, eu prefiro ir direto pro CREDENPES". O quê que vai acontecer? Se a porta do CREDENPES não tiver aberta, esse paciente pode ser uma baciloscopia positiva, vai estar disseminando em casa, na vizinhança e etc. etc. Eu acho que a demanda espontânea do CREDENPES ela deve continuar existindo. PAPS2

Na perspectiva do usuário, o estigma surge como um importante aspecto cuja repercussão psicossocial interfere em sua qualidade de vida. Entretanto, mais do que o receio de sofrer preconceito, observou-se que a dificuldade de acesso, a fragilidade do vínculo e a insatisfação com relação ao atendimento geraram, ao longo do tempo, a descredibilidade nos serviços de APS, resultando na busca pelo atendimento no CREDENPES e/ou a recusa à contrarreferência após o diagnóstico para a continuidade do tratamento na APS.

[...] Confiava neles não! [...] Ela (referindo-se à enfermeira da Estratégia Saúde da Família - ESF) falou assim "Você quer que eu ligo pra lá (CREDENPES) pra você tomar o remédio aqui?"- Eu falei: Não, não quero não! Quero não, minha filha, você não tava querendo nem me atender pra olhar o papel se eu tenho hanseníase ou não. 
Porque eu falei com ela assim: Olha, aqui, pra mim, se é hanseníase mesmo, da mais pior. - "Não, agora não dá não, só sexta-feira". "Só sexta-feira? Então, vai passar sexta, segunda e eu não vou! Vou vim não!"- [...] lá, eu acho que eu não tenho muita confiança com a enfermeira de lá não. Tenho medo [...] US5

De um modo geral, o CREDENPES foi destacado como um serviço que oferece melhor atendimento em relação à APS, sobretudo em função do acolhimento, suporte psicossocial e resolutividade em relação às demandas do usuário.

\section{[...] Eu não tenho nada a reclamar daqui (CREDENPES), graças a Deus, sabe? Todo o momento eu fui muito bem atendido, desde essa primeira consulta que eu cheguei [...] uma conversa boa, foi sempre sorriso, sempre acolhedor mesmo, sabe? [...] Não me deixaram faltar nada! Se eu tivesse que chegar aqui, igual eu tive dois momentos de reação do medicamento, eu vim sem marcar. Quando eu liguei, eles:- "Não, pode vim, a gente dá um jeito aqui, coloca você no meio de alguém"-, então, eu sempre fui muito bem atendido e sempre se prontificavam a atender a hora que eu precisasse. [...] Parece até mentira, né? Falando assim do serviço público. [...] US4}

Não obstante a isso, é válido destacar que a busca do usuário por melhor atendimento na atenção secundária faz com que este assuma, voluntariamente, o ônus financeiro do deslocamento ao CREDENPES, acarretando dificuldade de acesso e possíveis repercussões como o atraso no tratamento.

Tomei remédio um ano certinho [...] tinha dia que era dia de eu vim mesmo. Eu tirava dinheiro e guardava pra mim vim cá, senão, como é que eu vinha, né, sem dinheiro? [...] Tem Bolsa Família, é pouquinho mesmo, mas eu tiro dez reais, vinte... [...] não é muito que eu tenho não, ganho pouquinho, cento e vinte por mês. Tá bom. [...] Eu queria aqui mesmo (CREDENPES) por causa que aqui ninguém maltrata ninguém [...] US5

Evidenciou-se também a naturalidade, por parte dos profissionais da APS, em apontar o CREDENPES como local ideal e mais apropriado para o cuidado em hanseníase no município de Governador Valadares, além das dificuldades da APS em realizar ações relacionadas à atenção à hanseníase, como o acompanhamento do tratamento e no pós-alta.

[...] tem três anos que eu tô aqui (ESF), eu nunca recebi um paciente pra fazer dose aqui [...] Porque, como o CREDENPES é um local de sigilo, até pra nós eles não podem saber que me passaram essa história [...] Então, é complicado até pra gente abordar esse paciente. [...] Às vezes, no CREDENPES, eu tinha quatro, cinco (referindose ao número de pacientes cadastrados na ESF que realizaram acompanhamento no Credenpes), mas sabendo, eu tinha 1 [...] PAPS4

[...] Às vezes, demora, às vezes, nem tem a contrarreferência que a gente precisa saber [...] Os próprios pacientes que depois falam com a gente, "ah, eu tô tratando, eu tratei de hanseníase, já me deram alta”, entendeu? A gente não tá tendo essa contrarreferência. PAPS7

Discutiram-se aspectos operacionais que influenciam o atual modelo de atenção à hanseníase no município como o despreparo técnico da APS, a baixa oferta de capacitações e a rotatividade dos profissionais treinados. Entretanto, foi ponderado que a prática rotineira de encaminhamento do usuário é cultural e tem sido realizada também por profissionais capacitados. Neste sentido, atores mencionaram aspectos como o desinteresse dos profissionais da APS, sobretudo médicos.

[...] Nós temos médicos e enfermeiros que, pelo que eu sei, já passaram pela capacitação e não fazem. [...] o quê que é isso, passa por capacitação e não aprende? É falta de interesse, "amiga"! Falta de envolvimento com o que veio, com a própria capacitação [...] PCR8

Segundo os atores, a apropriação e a sustentabilidade do conhecimento adquirido nas capacitações são também comprometidas pela passividade na busca ativa e pelo hábito de encaminhamento direto para o CREDENPES.

[...] Eu já esqueci tudo. [...] Concordo. Porque não é uma doença tão prevalente e ainda a gente encaminha... [...] PAPS6

A acomodação, na perspectiva do profissional da APS, é também justificada como resultado da sobrecarga de trabalho nas unidades, do volume de atividades inerentes aos diversos programas e da instabilidade do quadro de recursos humanos, que gera um sentimento de "eterno recomeço" do processo de trabalho após a saída de médicos e outros membros da equipe.

Observaram-se, porém, a naturalização do atual modelo de atenção centralizado no CREDENPES e o entendimento distorcido dos profissionais de que há um "fluxo instituído" pela gestão municipal que legitima a prática de encaminhamento para a atenção secundária.

[...] Aqui, a gente centraliza. [...] Encaminha imediatamente. Aqui, é mais busca ativa, avaliação e encaminhamento do caso suspeito. Depois, eu não sei nem o quê que acontece. [...] tem esse fluxo também, já tá sedimentado na cidade. Talvez, por esse motivo, eu nunca tenha assumido antes. [...] eles pedem pra encaminhar, sabe? [...] a própria coordenação prefere assim, sabe, mandar para o CREDENPES [...] O município todo encaminha. Tem algum lugar que tá tratando na unidade básica? [...] PAPS6 
Foram discutidas, também, resistências encontradas à mudança do modelo proposta pela descentralização, entendida como a perda de controle do CREDENPES pelos casos de hanseníase no município. Dentre as consequências, foi apontado o medo da subnotificação da doença pela APS, que deixaria de realizar a suspeição para evitar a responsabilização pela continuidade do cuidado.

\section{[...] Eu entendo que a descentralização levaria a um melhor atendimento ao paciente, porque ele seria diagnosticado no local de residência dele, mas, às vezes, percebo que aí não é feito lá e nem encaminhado pra cá. Porque aí entra a questão: se eu diagnostico, eu tenho que tratar, então, é melhor eu nem ver a doença, que aí eu nem trato, nem diagnostico e nem encaminho. Então, eu questiono essa questão. Entendo que é bom, mas eu questiono a eficácia da descentralização [...] PCR9}

[...] Eu acho que algumas pessoas não querem permitir, muitas vezes, pela capacidade apresentada pela atenção primária. [...] eu percebo que o termômetro que eles têm aí é que se liberar, descentralizar, vai haver um descontrole. [...] PCR2

Em relação aos profissionais da APS, as resistências apontam para o estigma relacionado à hanseníase e a crença na necessidade do cuidado especializado, aspectos que geram o distanciamento dos profissionais.

[...] Eu, na minha opinião, eu acho que é coisa muito...é uma doença...né? [...] bem específica: infecto, dermato...eu acho que deveria ficar por lá mesmo. Porque é uma doença altamente contagiosa e aqui, às vezes, a gente [...] pode tá aí passando pro resto do povo. Então, acho melhor que fique lá com os especialistas [...]. Quando eu pego aquela manchinha, [...] corticoidezinho tópico, volta daqui 15 dias pra ver se melhorou. Melhorou, beleza! Não melhorou, eu mando pro dermato. Eu não fico com o paciente aqui não porque senão eu vou pegar e todo mundo que tá aí na espera pega também. [...] tipo assim, eu, se eu fosse a dona, secretária de saúde, dona dos negócios, eu não descentralizaria de forma nenhuma [...] PAPS9

Em relação à gestão municipal, apesar do reconhecimento da importância da descentralização, observou-se, dialeticamente, a acomodação com o modelo vertical do PCH no CREDENPES, sustentado pelo medo da descontinuidade do cuidado na APS, sobretudo diante da rotatividade e dificuldade de supervisão das equipes da APS.

[...] Eu acho que... medo. [...] é mais fácil controlar centralizado. Porque a cobrança e tudo, ela fica muito no centro de referência. [...] Se eu descentralizo, eu perco um pouco de como que vai ser isso. [...] pra gente também, eu tenho 57 equipes. [...] Você gerenciar tudo isso é muito mais complexo. Assim, dar o suporte pra todo mundo é muito mais complexo! É um sonho, eu acho que, assim, é o que tem que ser feito, é um sonho, é uma vontade, mas eu acho que existe um medo muito grande também de se fazer, de se perder, sabe assim? [...] GES1

Uma evidência da acomodação da gestão municipal com a estrutura vertical do $\mathrm{PCH}$ é a centralização dos poliquimioterápicos no CREDENPES vista, pelos profissionais, como um entrave operacional à descentralização.

[...] deveria ter a medicação certinho, igual manda pra nós, mandar pros PSFs, porque eles buscam aqui(CREDENPES) [...] deveria ter os medicamentos lá também, né? Não ficar na nossa responsabilidade aqui, que é o centro de referência. Porque eles vêm buscar o remédio, às vezes, o paciente atrasa, não tem ninguém pra buscar o remédio, entendeu? A gente passa por isso aqui. [...] PCR4

\section{DISCUSSÃO}

A descentralização do $\mathrm{PCH}$ persiste como um desafio no Brasi|3,5,8,11,23 apesar das diretrizes políticas reforçarem a necessidade de fortalecimento da oferta das $\mathrm{ACH}$ nos serviços de APS para a redução da carga da doença ${ }^{2,23}$. Pesquisas têm constatado fragilidades no acesso ao diagnóstico ${ }^{8,13,14}$ e acompanhamento da doença pela APS ${ }^{3,8,12,24}$, resultando no deslocamento do usuário para serviços distantes de sua residência ${ }^{5,9}$, bem como em diagnóstico tardio ${ }^{5,8}$ e dificuldades no seguimento dos $\operatorname{casos}^{3,5,8}$.

Estudo que analisou a situação epidemiológica da hanseníase no Brasil e sua associação com a descentralização das ações de controle evidenciou que o diagnóstico de casos de hanseníase, na APS, teve associação estatisticamente significativa com o aumento da taxa de detecção anual de casos novos de hanseníase por 100 mil habitantes, da taxa de detecção anual de casos novos de hanseníase na população de zero a 14 anos por 100 mil habitantes e da taxa de casos novos de hanseníase com grau 2 de incapacidade física no momento do diagnóstico por 100 mil habitantes 24 .

Em Minas Gerais, a descentralização do $\mathrm{PCH}$ tem sido incentivada a partir do investimento na ampliação da cobertura da Estratégia Saúde da Família (ESF) ${ }^{19}$, na capacitação de profissionais da $\mathrm{APS}^{25}$ e na formulação do plano estadual de enfrentamento da hanseníase ${ }^{26}$.

Pesquisa que avaliou a presença e a extensão dos atributos da APS de Governador Valadares na realização das ACH mostrou que o município possui alta orientação do escore geral, porém, com fragilidades nos atributos que compõem o escore derivado (orientação familiar, comunitária e profissional) segundo a experiência dos gestores, médicos, enfermeiros e $\mathrm{ACS}^{27}$.

Dialeticamente, os resultados mostram que o desenho técnico-assistencial da rede de atenção à hanseníase, em Governador Valadares, reproduz ainda a lógica da centralização do atendimento ao usuário à medida que o mantém sob a 
responsabilidade de especialistas sob o discurso que há um despreparo técnico da APS e baixa oferta de capacitações.

Por isso, a instituição normativa da política de descentralização ${ }^{23,28}$, por si só, não é capaz de reorientar o modelo de cuidado à hanseníase ${ }^{8}$, uma vez que os participantes do estudo ainda "mantêm articulação das ações cotidianas sem mudanças de ordens simbólicas"27:8.

A resposta adequada da APS às necessidades de prevenção e controle da endemia hansênica perpassa pelas competências, atitudes e habilidades dos profissionais na realização das $\mathrm{ACH}^{4,15}$ para promover a ruptura de práticas que fragilizam a efetivação da APS como ordenadora e coordenadora do cuidado na rede de atenção ${ }^{29}$.

A experiência dos profissionais da APS na realização do atendimento aos casos suspeitos, confirmados e aos contatos de hanseníase é determinante para que o serviço seja provedor de ações de controle da doença orientadas para os atributos da APS $^{15}$. Essas atividades compreendem a oferta contínua de ações para o usuário, a família e a comunidade ${ }^{8,2,2,}$, cuja sustentabilidade pode ser viabilizada mediante a troca de experiências com profissionais de referência ${ }^{5,11}$.

Contudo, as evidências apontam fragilidades importantes na capacitação profissional para o enfrentamento dessa importante doença negligenciada ${ }^{3,5,8,9,11,12,13}$. Também foi evidenciado um potencial limitado da estratégia de capacitação na sustentabilidade do processo de descentralização dos programas municipais ${ }^{20}$, expresso pelo aumento da detecção em períodos de treinamento e campanha ${ }^{30}$, com tendência posterior à "recentralização" do diagnóstico e tratamento em centros de referência ${ }^{20}$, demonstrando a complexidade da reversão do modelo de atenção à hanseníase.

Além da rotatividade ${ }^{3,8}$, a fragilidade na estrutura das unidades de APS quanto aos recursos materiais, medicamentos e insumos para a atenção à hanseníase $e^{9,10,11}$, a sobrecarga de trabalho dos profissionais ${ }^{11} \mathrm{e} o$ "gargalo" da demanda espontânea na APS por doenças crônicas não transmissíveis ${ }^{31}$ têm sido apontados como determinantes que contribuem para o encaminhamento do usuário com hanseníase para os centros de referência ${ }^{9,31}$.

Por outro lado, as diferenças no grau de descentralização dos programas de controle em áreas endêmicas revelam não somente disparidades tecnológicas entre os serviços de saúde, como também a heterogeneidade dos modelos de gestão programática e de priorização da hanseníase na política municipa| ${ }^{3,11,12,24}$.

Estudo que analisou a tendência da situação epidemiológica e operacional da hanseníase em Minas Gerais, no período de 2008 a 2018, mostrou que o Estado apresentou tendência decrescente para a detecção geral de novos casos, mas apontou cautela na interpretação desse achado, uma vez que pode expressar uma lacuna no processo de cuidado em saúde ${ }^{32}$.

A eficácia da vigilância em saúde ${ }^{14,15}$, em Governador Valadares, também está comprometida devido ao distanciamento dos profissionais da APS em relação à hanseníase. Evidenciouse o significado simbólico do estigma expresso no desejo de não se identificar com a doença e no entendimento de tratar-se de uma patologia de especialidade. Pesquisa realizada com profissionais das regiões Norte e Nordeste do Brasil apontou que o estigma tem prejudicado a descentralização de forma mais expressiva do que aspectos operacionais como a rotatividade e a capacitação ${ }^{33}$.

A prática de retenção do usuário nos centros de referência, em contrapartida, favorece a verticalização do cuidado em hanseníase e está na contramão do que é recomendado nas diretrizes para a implementação da rede de atenção à hanseníase ${ }^{28}$. Essa prática é apontada como resultado de fatores operacionais, sobretudo a inabilidade técnica dos profissionais da APS 5 .

Não obstante a isso, aspectos como a necessidade de manter a visibilidade política local e o medo da perda de espaço de trabalho após a descentralização têm sido apontados como determinantes sócio-histórico-culturais que influenciam a prática de retenção do usuário nos serviços de referência, reforçando o modelo vertical de atenção à doença $a^{33}$.

Estes aspectos transformam-se em fatores de retenção e demanda nos centros de referência, construindo, ao longo dos anos, valores coletivos simbólicos capazes de orientar o fluxo de atenção local ${ }^{34}$.

A influência dos serviços de referência para a população está, dentre outros aspectos, relacionada aos contextos históricos locais de serviços remanescentes à municipalização, a exemplo de hospitais que, após a implantação do SUS, permaneceram na rede assistencial como ambulatórios de referência, atraindo a demanda local de novos casos de hanseníase ${ }^{34,35}$.

Além disso, estudos apontaram o significado da superioridade dos centros de referência na perspectiva do usuário, relacionada às tecnologias e à qualidade do atendimento, associado à experiência de dificuldades de acesso nas unidades de APS ${ }^{20}$.

A insatisfação com o acolhimento dos profissionais e a fragilidade do vínculo na APS fazem com que os serviços de referência se tornem o primeiro serviço de escolha do usuário, apesar da barreira geográfica e do ônus financeiro associado ao deslocamento 4 . Há evidência de que "práticas e experiências exitosas, centradas no usuário e em suas necessidades, podem ser consideradas situações capazes de modificar os significados"27:8 da assistência prestada ao paciente de hanseníase nos serviços de APS.

Vaitsman (2000) reiterou que os significados sóciohistórico-culturais atuam de modo autônomo, condicionando comportamentos no âmbito das organizações públicas, e sua desconstrução não passa pela introdução formativa de políticas verticais, sendo este um importante desafio para a introdução de novos desenhos institucionais e/ou inovações gerenciais ${ }^{36}$.

Em uma perspectiva macroestrutural, as dificuldades impostas à descentralização do $\mathrm{PCH}$ nos municípios brasileiros revelam a disputa entre modelos de atenção distintos, que coexistem entre si, cuja configuração tecnológica no âmbito dos saberes e das práticas de saúde distingue-se intrinsecamente, gerando tensões e conflitos de poder no cotidiano da assistência e gestão do programa.

Apesar da ampliação da realização das ACH na APS 11,13,14,15,37, o modelo de atenção à hanseníase carrega, historicamente, características de movimentos ideológicos hegemônicos que construíram a saúde pública no Brasil, a exemplo do modelo sanitarista que deu origem às campanhas sanitárias e programas 
especiais. Estes têm, como características, a combinação de tecnologias fundamentadas nas disciplinas biológicas, a atuação no risco e os agravos de maior relevância epidemiológica de modo isolado e verticalizado. Este modelo exerce importante influência política e cultural junto às profissões de saúde, população e Estado, influenciando os modos de produção do cuidado e induzindo a reprodução de práticas que atuam como barreiras à consolidação da descentralização e à integralidade do cuidado ${ }^{35}$.

Nesse sentido, é válido afirmar que o modelo da APS, pautado na promoção da saúde, ainda persiste como desafio no campo das práticas assistenciais para a consolidação do próprio Sistema Único de Saúde, no sentido de consolidar-se não somente em sua dimensão jurídico-institucional, mas principalmente enquanto paradigma político-operacional capaz de reorientar as práticas de cuidado em saúde no sentido da integralidade ${ }^{38}$.

Uma das limitações do estudo foi a inviabilidade de renovação do Círculo Hermenêutico-Dialético, o que possibilitaria aos primeiros participantes terem acesso às construções conjuntas que se acumularam no decorrer do processo. No entanto, buscou-se sanar este aspecto durante as oficinas de negociação, nas quais foram apresentados aos participantes, de forma transparente $e$ criteriosa, os principais temas discutidos nas entrevistas individuais, com os respectivos fragmentos das falas dos participantes. Além disso, não foi realizado período de observação do campo pelo pesquisador, uma vez que se optou por negociar a participação dos sujeitos com os próprios profissionais e gestores, por tratarse de um cenário amplamente conhecido pelos pesquisadores, por meio de outros estudos realizados no município.

Destaca-se que os resultados da avaliação apontaram aspectos tanto favoráveis quanto desfavoráveis para todos os grupos de interesse, mostrando que a metodologia foi capaz de apreender e representar as reivindicações, preocupações e questões dos atores envolvidos.

\section{CONCLUSÃO}

Este estudo avaliou a descentralização do $\mathrm{PCH}$, em Governador Valadares, por meio de uma pesquisa avaliativa de quarta geração de abordagem qualitativo-participativa. Evidenciou-se a manutenção do modelo vertical de atenção à hanseníase, sustentado por determinantes sócio-histórico-culturais que foram apontados, pelos participantes, como os aspectos que se interpõem à descentralização das $\mathrm{ACH}$ no município.

A utilização da pesquisa avaliativa de quarta geração, de abordagem qualitativo-participativa, para a abordagem do problema de pesquisa permitiu desvelar as tensões entre os participantes de cada ponto de atenção à saúde que determinam a implementação do modelo centralizado de atenção à hanseníase: de um lado, há um questionamento, pelos profissionais, da referência sobre a efetividade da descentralização e, por outro lado, os profissionais da APS, baseados na crença da necessidade do cuidado especializado mediante o despreparo técnico da equipe de APS, afirmam que o encaminhamento do paciente ao CREDENPS sem a contrarreferência é o fluxo instituído no cotidiano de trabalho.
Nesse cenário, a APS encontra-se fragilizada para a realização das $\mathrm{ACH}$ na APS, tendo seu papel restrito à suspeição de casos e ao encaminhamento. Apesar disso, a APS não está configurada como a porta de entrada preferencial do usuário na rede de atenção à hanseníase em Governador Valadares, uma vez que o serviço da atenção secundária permite o acesso sem referência.

O fortalecimento da atenção primária, a educação permanente em saúde e o apoio político- institucional da gestão municipal à descentralização são estratégias potencialmente efetivas para a construção de uma rede de atenção no município. A participação efetiva da APS depende do redirecionamento do papel dos serviços com a ordenação do fluxo da porta de entrada pela APS, o apoio matricial e a participação da comunidade nas decisões sobre os modos de cuidado mediante a criação de vínculos efetivos com a população. Acredita-se que essas questões darão sustentabilidade ao processo de descentralização.

\section{CONTRIBUIÇÕES DOS AUTORES}

Desenho do estudo. Cristal Marinho Corrêa. Francisco Carlos Félix Lana

Coleta ou produção dos dados. Cristal Marinho Corrêa. Análise de dados. Cristal Marinho Corrêa. Francisco Carlos Félix Lana. Fernanda Moura Lanza. Ana Paula Mendes Carvalho. Interpretação dos resultados. Cristal Marinho Corrêa. Francisco Carlos Félix Lana. Fernanda Moura Lanza. Ana Paula Mendes Carvalho.

Redação e revisão crítica do manuscrito. Cristal Marinho Corrêa. Fernanda Moura Lanza. Ana Paula Mendes Carvalho. Francisco Carlos Félix Lana.

Aprovação da versão final do artigo. Cristal Marinho Corrêa. Fernanda Moura Lanza. Ana Paula Mendes Carvalho. Francisco Carlos Félix Lana.

Responsabilidade por todos os aspectos do conteúdo e a integridade do artigo publicado. Cristal Marinho Corrêa. Fernanda Moura Lanza. Ana Paula Mendes Carvalho. Francisco Carlos Félix Lana.

\section{EDITOR ASSOCIADO}

Maria Catarina Salvador da Motta

\section{EDITOR CIENTÍFICO}

Ivone Evangelista Cabral [1]

\section{REFERÊNCIAS}

1. Nery JS, Ramond A, Pescarini JM, Alves A, Strina A, Ichihara MY et al Socioeconomic determinants of leprosy new case detection in the 100 Million Brazilian Cohort: a population-based linkage study. Lancet Glob Health. 2019;7(9):e1226-36. http://dx.doi.org/10.1016/S2214109X(19)30260-8. PMid:31331811.

2. Ministério da Saúde (BR). Secretaria de Vigilância em Saúde, Departamento de Vigilância das Doenças Transmissíveis. Diretrizes 
para vigilância, atenção e eliminação da hanseníase como problema de saúde pública [Internet]. Brasília: Ministério da Saúde;2016.

3. Lanza FM, Lana FCF. Decentralization of leprosy control actions in the micro-region of Almenara, State of Minas Gerais. Rev Lat Am Enfermagem. 2011 jan/fev;19(1):187-94. http://dx.doi.org/10.1590/ S0104-11692011000100025. PMid:21412646.

4. Lanza FM, Vieira NF, Oliveira MMC, Lana FCF. Instrument for evaluating the actions of leprosy control in Primary Care. Rev Bras Enferm. 2014 maio/jun;67(3):339-46. http://dx.doi.org/10.5935/0034-7167.20140044. PMid:25054693.

5. Barbieri RR, Sales AM, Hacker MA, Nery JAC, Duppre NC, Machado $A L$ et al. Impact of a reference center on leprosy control under a decentralized public health care policy in Brazil. PLoS Negl Trop Dis. 2016;10(10):e0005059. http://dx.doi.org/10.1371/journal.pntd.0005059. PMid:27732610.

6. Standley C, Boyce MR, Klineberg A, Essix G, Katz R. Organization of oversight for integrated control of neglected tropical diseases within Ministries of Health. PLoS Negl Trop Dis. 2018;12(11):e0006929. http:// dx.doi.org/10.1371/journal.pntd.0006929. PMid:30462639.

7. Rodrigues RN, Niitsuma EM, Bueno IC, Baquero OS, Jardim CCG, Lana FCF. Hanseníase e vulnerabilidade da saúde em Belo Horizonte, Minas Gerais. Rev Min Enferm. 2017;21:e-997.

8. Saltarelli RMF, Seixas DHT. Limites e possibilidades na atenção ao portador de hanseníase no âmbito da Estratégia Saúde da Família. Rev APS. 2016 out/dez; 19(4):613-22.

9. Sousa GS, Silva RLF, Xavier MB. Hanseníase e Atenção Primária à Saúde: uma avaliação de estrutura do programa. Saúde Debate. 2017;41(112):230-42. http://dx.doi.org/10.1590/0103-1104201711219.

10. Leite TRC, Lopes MSV, Maia ER, Cavalcante EGR. Avaliação da estrutura da atenção primária à saúde na atenção à hanseníase. Enferm Foco. 2019;10(4):73-8.

11. Leal DR, Cazarin G, Bezerra LCA, Albuquerque AC, Felisberto E. Programa de Controle da Hanseníase: uma avaliação da implantação no nível distrital. Saúde Debate. 2017;41(esp):209-28. http://dx.doi. org/10.1590/0103-11042017s16

12. Souza MF, Vanderlei LCM, Frias PG, Souza MF, Vanderlei LCM, Frias PG. Avaliação da implantação do Programa de Controle da Hanseníase em Camaragibe, Pernambuco. Epidemiol Serv Saude. 2017;26(4):817-34. http://dx.doi.org/10.5123/S1679-49742017000400013. PMid:29211145.

13. Sousa GS, Silva RLF, Brasil-Xavier M. Hanseníase e atenção primária: um estudo avaliativo sob a ótica do médico. Rev Salud Publica. 2018;20(3):359-65. http://dx.doi.org/10.15446/rsap.v20n3.56109. PMid:30844010.

14. Vieira NF, Lanza FM, Lana FCF, Martínez-Riera JR. Avaliação dos atributos da atenção primária à saúde nas ações de controle da hanseníase. Rev Enferm UERJ. 2018;26:e31925.

15. Vieira NF, Lanza FM, Martínez-Riera JR, Nolasco A, Lana FCF. Orientación de la atención primaria en las acciones contra la lepra: factores relacionados con los profesionales. Gac Sanit. 2020;34(2):1206. http://dx.doi.org/10.1016/j.gaceta.2019.02.011. PMid:31053453.

16. Bosi MLM, Mercado FJ, organizadores. Avaliação Qualitativa de Serviços de Saúde: enfoques emergentes. 3. ed. Petrópolis: Vozes; 2013.

17. Genovez PF, Pereira FRO. "Drama" da hanseníase: Governador Valadares, as políticas públicas de saúde e suas implicações territoriais na década de 1980. Hist Cienc Saude Manguinhos. 2016;23(2):379-96. http:// dx.doi.org/10.1590/S0104-59702016000200004. PMid:27276042.

18. Guba EG, Lincoln YS. Avaliação de quarta geração. 1. ed. Campinas: Editora Unicamp; 2011.

19. Hartz ZMA. Histórico da avaliação. In: Brousselle A, Champagne F, Contandriopoulos AP, Hartz, Z. Avaliação: conceitos e métodos. 1. ed. Rio de Janeiro: Fiocruz; 2011.

20. Genovez PF, Pereira FR. Da lepra á hanseníase: Política pública, o cotidiano e o estigma a partir da memória de seus atores - Governador
Valadares (Década de 1980). Hist Questoes Debates. 2014;60(1):20528. http://dx.doi.org/10.5380/his.v60i1.38287.

21. Glaser BG, Strauss AL. The discovery of groundded theory. Chicago: Aldine; 1967.

22. Charmaz K. A construção da teoria fundamentada: guia prático para análise qualitativa. Porto Alegre: Artmed; 2009.

23. Ministério da Saúde (BR). Secretaria de Vigilância em Saúde. Departamento de Doenças de Condições Crônicas e Infecções Sexualmente Transmissíveis. Estratégia Nacional para Enfrentamento da Hanseníase 2019-2022. Brasília: Ministério da Saúde; 2019.

24. Vieira NF, Lana FCF, Rodrigues RN, Niitsuma ENA, Lanza FM. Avaliação da Atenção Primária: comparativo entre o desempenho global e as ações de Hanseníase. RECOM. 2019;9:e2896. http://dx.doi.org/10.19175/ recom.v9i0.2896.

25. Leroy FS, Coelho A CO, Niitsuma ENA, Gomes FBF, Lanza FM, Ribeiro G C et al. Educação permanente em saúde: a experiência do uso da educação a distância na capacitação em ações de controle da hanseníase. Em Rede. 2017;4(1):235-50.

26. Lanza FM. Avaliação da atenção primária no controle da hanseníase: validação de instrumentos e análise do desempenho de municípios endêmicos do Estado de Minas Gerais [tese]. Belo Horizonte: Escola de Enfermagem, Universidade Federal de Minas Gerais; 2014.

27. Silva JF, Fonseca DF, Silva J, Viegas SMF, Lanza FM. O cotidiano de trabalho da estratégia saúde da família: entre o real e o ideal. RECOM. 2019;9:e3488. http://dx.doi.org/10.19175/recom.v9i0.3488.

28. Secretaria de Estado da Saúde de Minas Gerais. Coordenadoria Estadual de Controle da Hanseníase. Plano de Enfrentamento da Hanseníase em Minas Gerais, 2019-2022 [manuscrito]. Belo Horizonte: Secretaria de Estado da Saúde; 2019.

29. Mendes EV. O cuidado das condições crônicas na atenção primária à saúde. Rev Bras Promoç Saúde. 2018;31(2):1-3.

30. Lanza FM, Rodrigues RN, Silva J. Integração ensino-serviço para realização de educação permanente em ações de controle da Hanseníase: relato de experiência. HU Rev. 2021;47:1-6.

31. Alencar CHM, Ramos Jr AN, Sena No SA, Murto C, Alencar MJ, Barbosa JC et al. Diagnóstico da hanseníase fora do município de residência: uma abordagem espacial, 2001 a 2009. Cad Saude Publica. 2012;28(9):1685-98. http://dx.doi.org/10.1590/S0102-311X2012000900008. PMid:23033184.

32. Ariana SM, Lago KS, Costa CM, Bueno IC, Rodrigues RN. Tendência da situação epidemiológica e operacional da hanseníase no estado de Minas Gerais (2008 - 2018). Saúdecoletiva. 2020;10(56):3122-31.

33. Raposo MT, Nemes MIB. Assessment of integration of the leprosy program into primary health care in Aracaju, state of Sergipe, Brazil. Rev Soc Bras Med Trop. 2012 abr;45(2):203-8. http://dx.doi.org/10.1590/ S0037-86822012000200013. PMid:22534993.

34. Smith WCS. Sustaining anti-leprosy activities requires radical changes Lepr Rev. 2010 dez;81(4):281-3. http://dx.doi.org/10.47276/lr.81.4.281. PMid:21313970.

35. Correia CMF, Pimentel NSN, Fialho VML, Oliveira RML, Gomide M, Heukelbach J. Fatores associados à alta demanda de pacientes com hanseníase em centro de referência em Manaus, Amazonas. Cad Saude Colet. 2008 jan;16(2):169-80.

36. Vaitsman J. Cultura de organizações públicas de saúde: notas sobre a construção de um objeto. Cad Saude Publica. 2000;16(3):847-50. http:// dx.doi.org/10.1590/S0102-311X2000000300033. PMid:11035524.

37. Rodrigues RN, Arcêncio RA, Lana FCF. Epidemiologia da hanseníase e a descentralização das ações de controle no Brasil. Rev Baiana Enferm. 2021;35:e39000. http://dx.doi.org/10.18471/rbe.v35.39000.

38. Paim JS. Modelos de Atenção à Saúde no Brasil. In: Giovanella L, organizadora. Políticas e sistema de saúde no Brasil. 2. ed. Rio de Janeiro: Editora FIOCRUZ; 2012.

\footnotetext{
a Manuscrito extraído da dissertação de mestrado "Avaliação do Programa de Controle da Hanseníase no Município de Governador Valadares, Minas Gerais Brasil", da autora Cristal Marinho Corrêa, sob a orientação de Francisco Carlos Félix Lana. Defendida no ano de 2016. Programa de Pós-Graduação em Enfermagem da Universidade Federal de Minas Gerais.
} 